\title{
PARENTESCO E COSMOPOLÍTICA NA ATUAÇÃO DA CHEFIA AMERÍNDIA: EXPERIÊNCIAS ETNOGRÁFICÁS JUNTO AOS KAIOWA DE MATO GROSSO DO SUL, BRASIL ${ }^{1}$
}

JOSÉ HENRIQUE PRADO ${ }^{2}$

UFMS

\begin{abstract}
Resumo
O movimento é constante na política Kaiowa e a ausência de uma instituição política de grande alcance permite muita autonomia e dinamicidade para que cada parentela tenha muita liberdade para tomar decisões, seguindo assim por um caminho de composição e decomposição constantes do social através da política. Para que a chefia ou o casal de líderes mantenha um grupo no entorno de si, é preciso muita habilidade. Inicialmente é enfrentado o desafio de criar o grupo e em seguida é preciso que ele seja mantido no tempo. O objetivo principal deste trabalho é discutir as relações existentes entre o social, o político e o parentesco. Desse modo, fez-se necessário traçar um percurso etnográfico (e de trabalho de campo) durante a escrita para se chegar à compreensão da tese de que a chefia ameríndia entre os Kaiowa não é a pessoa de poder e, sim, de prestígio.
\end{abstract}

Palavras-chave: cosmopolítica, parentesco, liderança indígena, Kaiowa, Mato Grosso do Sul.

\begin{abstract}
Movement is constant in Kaiowa politics and the absence of a far-reaching political institution allows a lot of autonomy and dynamicity. So that each kin has much freedom to make decisions, thus following a path of composition and decomposition of the social through politics. For the leader or the couple of leaders to maintain a group around you, it takes a lot of skill. Initially the challenge of creating the group is faced and then it needs to be kept in time. The main objective of this work is to discuss the relations between the social, the political and the kinship. Thus, it was necessary to trace an ethnographic (and fieldwork) course during the writing to arrive at an understanding of the thesis that the Amerindian leadership among the Kaiowa is not the person of power, but rather of prestige.
\end{abstract}

\footnotetext{
${ }^{1}$ Este texto é baseado no capítulo IV da dissertação de mestrado em antropologia defendida pelo autor (Cf. PRADO, José Henrique. Através do Prestígio: A atuação da chefia ameríndia entre os Kaiowa da Terra Indigena Pirakuá". Dourados, MS: Dissertação e Mestrado, Antropologia da UFGD, 2013, 116 f.) e foi utilizado como subsídio para exposição na mesa redonda Trabalho Antropológico e Organização Política Indígena, realizada em 8 de abril de 2017 durante a VI Reunião de Antropologia de Mato Grosso do Sul, na Universidade Federal de Mato Grosso do Sul.

${ }^{2}$ Graduado em Ciências Sociais pela UFMS e mestre em Antropologia Sociocultural pela UFGD. Atualmente, supervisor de formação do núcleo da UFMS na Ação Saberes Indígenas na Escola e supervisor pedagógico do curso de pós-graduação lato sensu de formação de professores na temática Antropologia e História dos Povos Indígenas (AHPI), FACH-UFMS. prado.jhenrique@gmail.com .
} 


\section{Introdução}

O papel da liderança política nas sociedades indígenas constitui-se muito mais através de um status de "prestígio", como pensou Pierre Clastres (2003), do que de "poder". Para Clastres, "prestígio não significa poder, e os meios que o chefe detém para realizar sua tarefa de pacificador limitam-se ao uso da palavra" (2003, p. 223). Sendo perceptivelmente de incumbência da pessoa que detém o status de prestígio, de chefia, a tarefa de mediar conflitos entre pessoas, famílias ou parentelas, principalmente pelo uso de suas habilidades discursivas.

É necessário então fazer uma reflexão: o que seria esse status de prestígio? De que maneira ele se amplia ou é reduzido? E, finalmente, quais elementos/coisas/qualidades estão ligadas ao acúmulo de prestígio por determinadas pessoas que ocupam cargos de liderança entre os Kaiowa?

O texto que se segue tem a pretensão de expor reflexões antropológicas elaboradas a partir de um projeto de pesquisa desenvolvido durante o curso de mestrado em antropologia. Em grande parte, são reflexões que se desdobraram a partir de leituras de outras etnografias e textos teóricos da área de etnologia indígena e de trabalho de campo na Terra Indígena Pirakuá, entre os anos de 201 1, 2012 e 2013.

A Terra Indígena Pirakuá é uma terra localizada próximo à fronteira entre o Brasil e o Paraguai, no município de Bela Vista, estado de Mato Grosso do Sul. No momento da pesquisa, o Pirakuá (como comumente é chamado pelos moradores) contava com uma população aproximada de 400 pessoas, em um contexto de grande relacionamento com outras aldeias Kaiowa e Guarani .

Em resumo, os itens que se seguem estão organizados da seguinte maneira: Mba'Ejehu, o primeiro item, foi construído com a ideia de ser uma espécie de ensaio etnográfico, introduz o leitor ao ponto de vista do autor, quando da realização do trabalho de campo e tenta colocar em tela um pouco dos relacionamentos sociais de uma família kaiowa. De início, o texto aparenta ser deslocado dos moldes mais formais da escrita acadêmica. No entanto, pretende-se criar um cenário que auxiliará o leitor a fazer correlações no decorrer da leitura dos itens seguintes. Na segunda parte, Interações entre o parentesco e a política, procuro descrever e refletir acerca das modalidades de organização social dos Kaiowa, a interação entre as relações de parentesco e as práticas políticas,

\footnotetext{
${ }^{3}$ Principalmente com as aldeias Ñhanderu Marangatu e Campestre.
} 
propondo uma leitura que associa estas práticas com as esferas sociais e de cooperação. Grupos de suporte político e econômico do Pirakuá compõem a terceira parte do texto, na qual busquei criar (singelamente) um modelo de explicação para as unidades políticas que se formam entre os Kaiowa; Na quarta parte do trabalho, A chefia kaiowa e o prestígio, retomo as questões apresentadas nesta introdução e busco construir uma discussão sobre as forças nas quais se opera a chefia entre os Kaiowa; $O$ último item, Atributos qualitativos da chefia ameríndia, tenta realizar um fechamento deste trabalho, apresentando características e qualidades da atuação da liderança política kaiowa, correlacionando com outras etnografias sobre povos ameríndios da América do Sul.

\section{Mba'Ejehu}

Nem bem os primeiros raios de sol da manhã começam a apontar no céu e Ava Yvyra'i já está pegando a lenha ainda úmida do sereno que caiu durante a madrugada.

Ava Yvyra'i leva os troncos e toras de guariroba, cortados no dia anterior, para a tataypy; a cozinha da moradia. Calmamente, ele acende o fogo e começa a aquecer o corpo enquanto Jacy Tata Poty, sua esposa, chega com uma vasilha de metal com água ainda fria para colocar sobre uma grade de ferro que está sobre o fogo recém aceso.

Nenhuma palavra é dita, apenas observo calmamente o dia que começa seu movimento - até que Ava Yvyra'i me convida a sentar "d'jaha jaguapy".

Fora da tataypy ouvem-se os pássaros cantarem na mata que rodeia o okarapy; terreiro ocupado pela família.

Enquanto a água aquece, Ava prepara uma cuia com ka'a para tomar o primeiro mate do dia. Os primeiros raios de sol, já bem acesos, clareiam as copas das árvores mais altas, penetrando aos poucos a mata e recolhendo o orvalho novamente para a atmosfera.Conjuntamente a água quente passa pelo mate e aquece nossos corpos lentamente ainda duros e sonolentos.

O mate é servido por Ava, que fala com voz mansa e pausada. A rotina matinal é tematizada por uma fala que relembra momentos vividos no yma guare; em tempos antigos. Nessa manhã, Ava fala do tempo de criança e das expedições de caça que realizava em família, acompanhado de seus pais e dos avós, do tempo em que ainda havia poucas cercas de fazenda na região. Conta que passavam alguns dias coletando e caçando na mata, como uma viagem de veraneio em família. Por lá estabeleciam um acampamento onde pescavam, riam e comiam.

O sol está mais forte, já não se pode mais ver a lua no céu. Ava diz, agora em português, "é a moto do Kurumbe"... Passado algum tempo consigo perceber o som do motor. Kurumbe é o único filho homem de Ava, que teve com Jacy mais três filhas, hoje já casadas. Kurumbe senta conosco na tataypy para o mate, enquanto os dois netos de Ava que o 
acompanham brincam no okarapy com os jagua (cachorros), que ainda bocejam preguiçosamente enquanto balançam seus rabos em sinal de bom dia.

Jacy prepara a primeira refeição do dia: peixe ensopado, pescado por Kurumbe na noite anterior. E alguns cascudos, assados nas cinzas ao lado do fogo que permanece aquecendo a água. Kurumbe avisa que deixará as crianças aos cuidados da avó para ir pescar em um afluente mais distante da vertente do Rio Apa, que passa logo abaixo da sua casa.

Com o dia já bem claro, reinando o sol em um esplêndido céu azul, Ava sai da tataypy para iniciar os trabalhos na construção da nova tataypy para a sua esposa: "aquela já está muito velha e não tem mais conserto", por isso seu empenho nos últimos dias para finalizar a nova construção.

Enquanto conversávamos sobre antigas aldeias da região do Rio Apa, Jacy se estica no beiral da janela e anuncia "ed'ju tembi'u"... a comida está pronta! As crianças largam a bola, eu e Ava seguimos em direção a tataypy. Para Ava a primeira refeição do dia tem que ser reforçada, pois o trabalho é sempre puxado, e "esse negócio de comer pão de manhã não sustenta... tem que comer carne mesmo, mandioca ou carreteiro".

Ñahatĩ, filha mais nova do casal, chega, logo após o termino do desjejum, carregando sua filha pequena. Ava faz uma pausa em seu trabalho para tomar tereré com Ñahatĩ. A conversa é sobre a escola, onde Ñahatĩ é professora. Ava faz um longo discurso dizendo que os professores precisam aprender que é importante se transformarem em yvyrad'ja. Jacy traduz o termo dizendo que o mesmo faz referência a um aprendiz, a alguém que está próximo de um mestre.

Para Ava, as lideranças novas e os professores devem tornar-se yvyraid'ja, pois são os "caciques" - ñanderu (rezador) e o mburuvicha (liderança política) - que sabem o verdadeiro passado: "nós temos um passado e os professores tem que saber". De repente a fala de Ava Yvyra'i é interrompida pelos gritos de Akekẽ, esposo da agente de saúde da região do córrego Palmeiras. Akekẽ chega ofegante, falando em guarani, apontando para a mata e gesticulando muito. Um dos mitã (criança) olha para mim com os olhos arregalados e diz: "onça!".

"Onça?", questiono sem compreender de imediato.

Todos se levantam rapidamente, Ava Yvyra'i pega seu facão, as crianças se armam (lanças, foices, podão e os estilingues, que raramente saem do pescoço). Decido seguir o grupo, ainda sem entender o que estava acontecendo.

Próximo à casa de Akekẽ seguimos por um tape po'i, uma trilha estreita que adentra a mata. Os dois quilômetros de caminhada são percorridos em pouco tempo, até chegarmos a um grupo com dois homens e duas mulheres que espreitavam uma jaguatirica no alto da árvore.

Akekẽ é o primeiro a tentar acertá-la com uma flecha, mas percebe que o animal está em um galho muito alto, difícil de mirar. Ava sai em disparada ao centro da aldeia para buscar uma espingarda. Sentamos para esperar o retorno de Ava. Nesse tempo Ñahatĩ me diz que a jaguatirica 
"come muito as criações e pode acabar atacando alguma criança pequena", justificando a caçada.

Ava retorna acompanhado de outro kaiowa, dono da arma; só havia quatro projéteis de calibre 22 . Os três primeiros foram usados pelo dono do flobé, que acertou apenas um no pescoço do animal sem ser fatal.

Ava disse que daria o último disparo. Bam! Certeiro. No ouvido da jaguatirica, que cai de quase vinte metros e logo é recolhida pelos homens que estavam aguardando sua queda.

As crianças se aproximaram do animal e passam a mão em seu couro. Ava disse que não comeria a carne pois esse tipo de animal só pode ser comido por quem tem o domínio da língua das onças, e dá o animal abatido a um ancião, Carai, pedindo apenas o couro para si.

No caminho de volta para a casa, com um brilho nos olhos, Ava celebra o êxito da caçada com sua filha e netos, rememorando em voz alta outras histórias das caçadas bem-sucedidas. Essa expedição passa a ser mais uma no repertório de um grande caçador kaiowa.

\section{Interações entre o parentesco e a política: esferas sociais de cooperação}

Se deixarmos de considerar o equilíbrio como objetivo, não haverá mais lugar para falar em ameaça ao equilíbrio ou em esforço para a sua restauração (Perrone-Moisés, 2011, p. 870).

Pretendo desenvolver a ideia de que as relações políticas são, em parte, determinadas pelas relações de parentesco e de afinidade. Podendo ser apreendidas também pelas manifestações no campo da cooperação econômica entre grupos de pessoas ligadas através das relações de parentesco e das relações de afinidade. Para designar esses grupos, utilizarei o termo "grupos de suporte", realizando uma apreciação teórica análoga aos escritos de Clastres (2004) em seu ensaio A Economia Primitiva, no qual realiza a escrita do prefácio à obra de Marshall Sahlins $(1976)^{4}$, considerando que se torna impossível pensar as relações econômicas no exterior das relações políticas.

Clastres, ao falar da obra de Sahlins, afirma que as sociedades primitivas $^{5}$ são compostas de "unidades de produção e consumo". Com

\footnotetext{
${ }^{4}$ Prefácio escrito por Pierre Clastres à obra de Marshall Sahlins, Âge de Pierre, age d'abondance (Paris: Gallimard, 1976). A obra em questão tem como título original Stone Age Economics.

${ }^{5} \mathrm{O}$ uso do termo sociedades primitivas nesse texto remete-se à definição formulada por Pierre Clastres (2003; 2004), baseada na divisão das sociedades em primitivas (contra o Estado) e com Estado (em suas diversas formas). $\mathrm{O}$ termo é positivado pelo autor, servindo como uma maneira de definir claramente um campo de estudos para a antropologia política, ao mesmo tempo em que refuta e justifica o uso dessa divisão de maneira positiva, não mais encarando as sociedades não ocidentais como incompletas politicamente, estando essas em estágios primários do desenvolvimento político social da humanidade, mas sim baseando-se na ideia de completude política de ambas. Porém, tendo o poder, enquanto categoria
} 
efeito, cada uma dessas unidades funciona como um grupo autônomo do conjunto da sociedade. Isso é justificado pelo fato dessas unidades de produção e consumo - aqui, no caso, definidas como grupos de suporte - apresentarem "tendências centrífugas", ou seja, cada grupo de suporte, sendo um grupo econômico e político, busca sua independência em relação aos outros grupos que compõem o corpo do social. E também "tendências centrípetas", ou seja, cada família e pessoas que compõem o grupo de suporte buscam sempre alternativas para escapar de uma centralização em apenas um cabeçante. Como nos indica Perrone-Moisés (2011):

Afinal, ser, entre os ameríndios, é sempre devir; devir contrário, acima de tudo (Viveiros de Castro, 2009 et passim). [...] sugere, com efeito, uma constante dinâmica entre tendências centrípetas e tendências centrífugas; igualmente perceptível no ciclo de vida das aldeias, entre constituição (fundação), crescimento e dissolução (abandono) (PERRONE-MOISÉS, 2011, p. 868).

Portanto, é importante que a reflexão seja sempre feita levando em consideração esses elementos que perpassam a visão - ou cosmovisão empreendida pelos ameríndios. Ao modo que Perrone-Moisés (2011) propõe que esse movimento da política ameríndia que interage dinamicamente através dessas forças contrárias e não complementares, pois se o fossem chegaríamos à ideia de uno - e bem sabemos as ressalvas feitas por Clastres em relação a tal caráter de unidade abominado por sociedades que lutam permanentemente contra a formação de um Estado. Desse modo, deve-se observar e pensar o modelo a seguir de maneira dinâmica; ou através de um movimento pendular.

A "filosofia da chefia" estaria englobada num pensamento segundo o qual o social, como tudo mais, situa-se no intervalo de oposição entre ser e não ser, nem uma coisa nem outra, tampouco a soma dos dois. Uma coisa e outra. Feita de relações entre polos opostos, a política entre os ameríndios parece bem ser (também) movimento entre-dois. Movimento pendular cujo retorno é sempre deslocado, sempre transformado, de modo que o ponto de "chegada" jamais é exatamente o de "partida": quase o mesmo, mas não completamente. "Perpétuo desequilíbrio", sempre (PERRONE-MOISÉS, 2011, p. 869).

de análise dos meandros políticos, lugar e funcionamento diferentes em cada uma delas - nas sociedades contra o Estado e nas sociedades com Estado. 
O sistema social kaiowa apresenta uma gama variada de esferas que determinam a proximidade das relações econômicas e políticas entre as parentelas. Pereira $(1999 ;$ 2004) expõe, através de um modelo concêntrico, essas escalas de interação e solidariedade, das quais pretendo aqui suscitar quatro. Utilizando como recurso metodológico a descrição das unidades sociológicas de menor abrangência, passando às mais gerais - nas palavras de Pereira (2004, p. 48), "nas quais algumas dessas unidades são englobadas por outras de maior amplitude".

Diferente do que aponta Clastres, os relacionamentos econômicos e políticos não se dão de maneira generalizada entre os Kaiowa, pois existem esferas cosmológicas e sociais, que organizam e dão sentido às relações, determinando, assim, o sentido e a forma como são construídas e articuladas as redes e esferas de reciprocidades.

Como afirma Pereira (2004):

A conduta econômica entre os Kaiowa não se pauta por uma reciprocidade generalizada, como nos sugeriria uma leitura acrítica da bibliografia. Na verdade, combina a existência de pequenos círculos de pessoas que se consideram próximos e entre os quais existe um alto grau de solidariedade, com unidades sociológicas maiores e mais abrangentes (PEREIRA, 2004, p. 49).

Acreditando que é através da observação dessas esferas sociais de interação que se torna possível um caminho para observar a formação, a manutenção e a interação dos grupos de suporte do Pirakuá, que se constituem como políticos e econômicos, possibilitando, dessa maneira, o recorte para a observação aqui pretendida. São elas:

- Che ypykykuera, ou o "fogo familiar", seria a unidade de solidariedade mais íntima e intensa da vida de um Kaiowa, pois esta unidade - que pode ser entendida nos termos do pesquisador como a família nuclear - é formada basicamente por pais, filhos e agregados, sendo a "unidade mínima fundamental", ordenadora das relações em um nível microssociológico, contida pelas relações econômicas. Trata-se da esfera de relacionamento com maior autonomia. $O$ termo tem como significado aproximado "meus ascendentes próximos, da mesma origem".

Qualquer pessoa tem que estar ligada a um fogo para que sua existência social se torne viável, quando a pessoa rompe com um fogo por casamento ou dissensão, imediatamente se insere num outro fogo (PEREIRA, 1999, p. 83);

- Ñemoñare ("minha prole"), ou descendentes, é constituída pelo "agrupamento de um certo número de fogos e tem como base a ênfase nas relações de consanguinidade que os une" (PEREIRA, 
2004, p. 155). O che ñemoñare é basicamente delimitado pelo reconhecimento de um ancestral em comum a todos - o que torna o grupo semelhante entre si - demarcando essa esfera do sistema social kaiowa.

- Jehuvy pode ser compreendido através do verbo "jehu", que pode ser traduzido para o verbo em português "ajudar"; já o termo jehuvy enfoca a cooperação e significa "aqueles que se ajudam". Essa esfera do modelo concêntrico desenvolvido por Pereira (2004), designa núcleos de adensamento de fogos no interior da parentela extensa (te'yi). Segundo Pereira (2004), geralmente o jehuvy é formado por um número pequeno de fogos que pode variar de dois a seis, e sua principal característica de agregação se dá através da economia, diferentemente do ñemoñare, espaço de predominância da consanguinidade.

- Te'yi, ou "parentela", apresenta-se como a esfera de agregação mais ampliada de solidariedade, baseada principalmente em relações políticas e composta principalmente por relações consanguíneas, que, porém, permitem a incorporação e o englobamento de afins e aliados, reunindo um número variável de fogos domésticos. A identificação de uma parentela normalmente é dada através do nome de seu cabeçante; é muito comum ouvir "tal pessoa da família do sr. Fulano".

No Pirakuá, tive a oportunidade de visualizar com mais proximidade a interação entre as parentelas que residem na área e o relacionamento nas diversas esferas do sistema social kaiowa apontadas acima. Observando as formas de cooperação entre elas, pude apreender que, de fato, o planejamento econômico e político mais estratégico está contido, principalmente, nas relações do fogo familiar (ypykukuera) e que o âmbito mais amplo da parentela, a te'yi, acaba sendo ordenado através do casal de cabeçantes ${ }^{6}$, denominados pelos termos de hi'u para o homem e ha'i para a mulher, membros estes que ocupam um lugar central na hierarquia da parentela.

O hi'u e a ha'i são pessoas geralmente mais velhas, ainda bastante ativas economicamente, com filhos já casados que compõem o entorno da parentela. É possível pensar que as redes formadas e as esferas de organização parental e de afinidade dos Kaiowa são compostas por um centro (referenciado pelo casal de cabeçante - hi'u e há'i) e por uma periferia.

Em termos sócio-políticos, a parentela possui um centro e uma periferia. O centro constitui uma espécie de cidadãos de primeira classe, uma elite política que acumula prestígio, poderes, atribuições e privilégios,

\footnotetext{
${ }^{6} \mathrm{O}$ "casal de cabeçantes" apresenta em uma relação matrimonial estável, servindo como referência - muitas vezes econômica e política - para o restante da parentela. Tendo esse casal a capacidade de manter próximo de si suas filhas e seus filhos casados, netos e, em alguns casos, bisnetos.
} 
sendo formada pelos fogos vinculados diretamente ao cabeça da parentela, geralmente seus parentes próximos. A periferia, por sua vez, é composta pelos fogos mais distantes do cabeça de parentela em termos genealógicos e políticos (PEREIRA, 2004, p. 126).

Para tentar visualizar essas relações do modelo concêntrico e também a ideia de centro e periferia da parentela, foi elaborada uma figura (segue abaixo) que busca de maneira singela ilustrar esses relacionamentos:

Figura 1: Ilustração das esferas de relacionamento no modelo concêntrico

\section{Che ypykukukera}

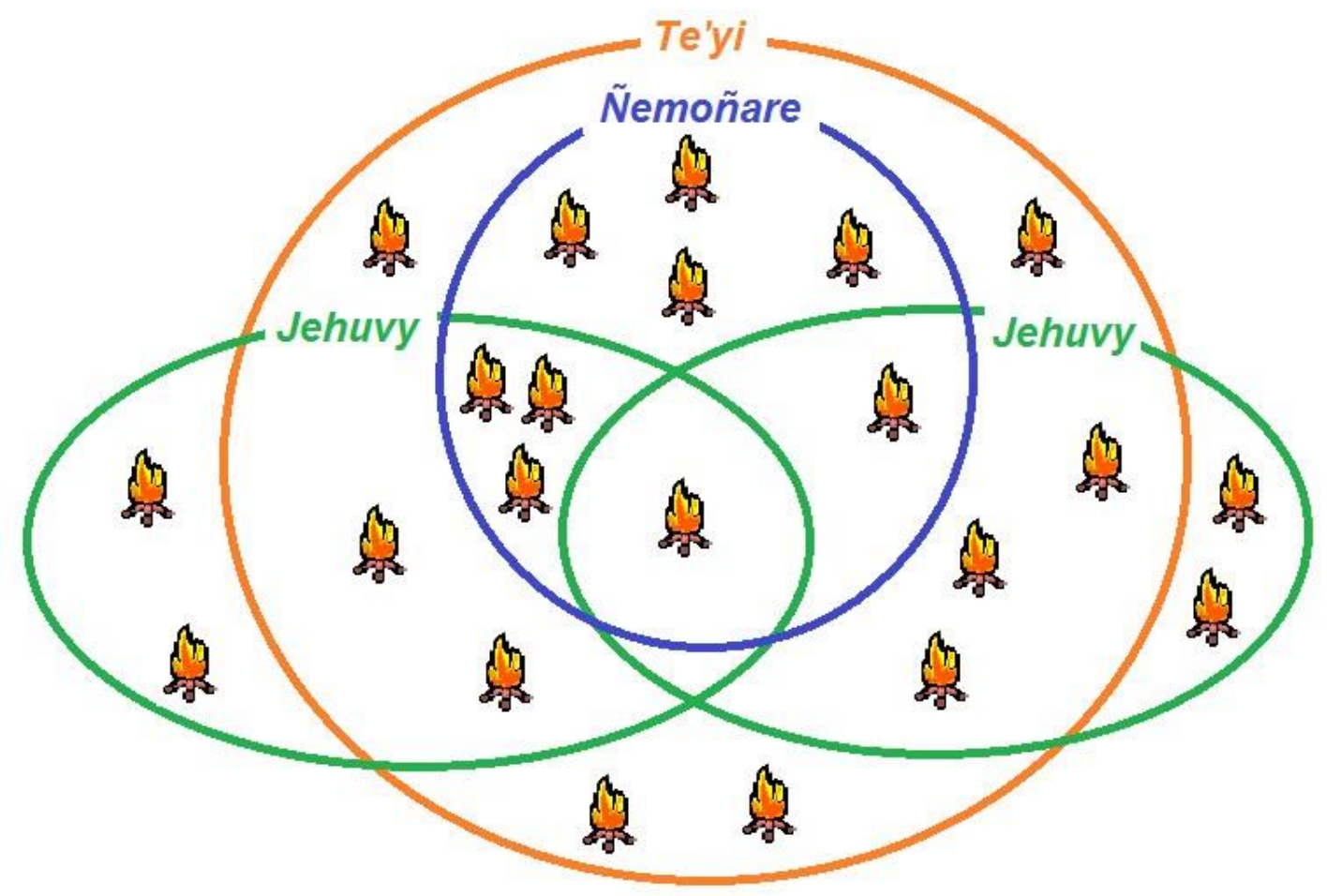

Fonte: Elaboração própria.

É possível pensar a mulher como a base da reprodução física e cultural do povo Kaiowa e Guarani, pois sem a mulher não há fogo. Assim, a mulher desempenha um papel muito importante nas relações mais horizontais e cotidianas; é através das atividades que desempenha a mulher Kaiowa que se institui e que se organiza a vida social das pessoas do che ypykukuera. 
A existência do fogo enquanto unidade sociológica depende da existência do fogo culinário aceso no interior da casa, ou em um pequeno compartimento construído ao lado desta, funcionando como cozinha externa. O fogo culinário é o símbolo da vida, portanto, nunca deve se apagar. Mesmo nos momentos em que não estão sendo preparadas refeições, é comum encontrar uma chaleira com água quente ou batatas [doce] e frutos assando sobre a brasa, um dos passatempos das crianças (PEREIRA, 2004, p. 68).

Cada fogo doméstico é autônomo e responsável pelo sustento das pessoas que fazem parte dele. Portanto, cada família nuclear é responsável pela produção de seu sustento. Dessa forma, as práticas agrícolas, principal atividade de sustento da maioria das famílias no Pirakuá, são desenvolvidas no âmbito da família nuclear à beira de seu próprio fogo.

Em diversos momentos foi possível constatar que o casal de cabeçantes é sempre consultado para a tomada de decisões que necessitam de uma habilidade maior, assim como é comum que esse casal ajude financeiramente, pois uma das características para estar em lugar de referência dentro da parentela (te'yi) é ter a capacidade de produzir um excedente, que, no caso dos Kaiowa do Pirakuá, está diretamente ligado a ter uma roça grande o suficiente para suprir possíveis necessidades que venham a ter os parentes que residem em outros fogos domésticos. O casal de cabeçantes também deve ter condições financeiras para a obtenção de produtos e serviços negociados com as sociedades do entorno do Pirakuá.

Essa capacidade de produzir excedente foi possível de ser observada durante o trabalho de campo no Pirakuá. A grande movimentação de pessoas que pude observar no okarapy de alguns cabeçantes de parentelas apontou para uma relação intrínseca das reciprocidades e da (re)produção econômica. Talvez em uma observação mais atenta seja possível compreender esse movimento como o próprio jehuvy, ou seja, como uma das esferas de compreensão do sistema social kaiowa, com tendências mais voltadas para a cooperação econômica (o que não deixa de ter implicações políticas). Durante o tempo que estive no Pirakuá, era muito comum na casa do casal de cabeçantes em que eu estava alojado o trânsito de pessoas que chegavam para trocar serviços (limpeza de roçado, pequenos consertos, alimentar animais, debulhar milho...) por produtos da roça do casal, pelo pagamento de diárias de trabalho e também por produtos industrializados advindos de comércios da cidade.

Outro fator importante de status do casal de cabeçantes é dispor de membros ocupantes de cargos assalariados na escola, no posto (ambulatório), no serviço de saúde ou mesmo em trabalhos contratados por produtores rurais da região. É o caso, por exemplo, da família de uma das lideranças mais importantes e respeitadas do Pirakuá, que tem 
atualmente suas três filhas trabalhando como professoras (duas no Pirakuá e uma no Campestre), o único filho homem, em fazendas da região entre Bela Vista e Antônio João, e um dos genros, morador do Campestre, como agente de saúde no polo de atendimento da SESAI de Antônio João. Essas relações permitem ao casal privilégios na aquisição de produtos que só podem ser obtidos na cidade (óleo, açúcar, sal, sabão em pó, refrigerante, bolachas, etc.). Dessa maneira, colocam o casal em uma posição de privilégio para o estabelecimento de trocas com pessoas de outras famílias e de outros grupos de suporte no Pirakuá.

Durante o período que permaneci na casa do casal Jorge e Darci, quase diariamente aparecia algum parente, chamado por eles muitas vezes de "parente'i" ${ }^{7}$, oferecendo serviços que em troca eram recompensados com as refeições durante o tempo de serviço e com produtos agrícolas da roça do casal. A atuação do casal de cabeçantes pode ser pensada através da circulação da parentela na sua casa e também pela frequência com que as filhas e os filhos casados os visitam para negociar demandas que acreditam ser essenciais. Nessas visitas, é comum a socialização ser feita em meio a uma roda de tereré, sendo a bebida servida por uma criança que, na maioria das vezes, não participa da conversa, permanecendo apenas como ouvinte dos assuntos discutidos.

Esses intervalos dedicados ao tereré, além de serem momentos de descanso, dedicados a conversas cotidianas, servem também para o pedido de conselhos, para pleito de auxílios financeiros para viagens à cidade com o objetivo de comprar produtos ou algum tipo de serviço necessário, para os quais os parentes do entorno da parentela não têm condições financeiras para realizar sem a ajuda do casal de cabeçantes que quase sempre apresenta estabilidade e maior disponibilidade de recursos.

Como foi o caso de um dos filhos de Jorge e Darci, que estava se preparando, durante o período que estive em campo, para tirar habilitação de motorista. A habilitação seria custeada pelo pai; em contrapartida - sempre que possível - os filhos auxiliam o pai em serviços diversos, como o corte de madeira, o conserto de objetos, entre outros. Porém, essa prestação de serviços não se estabelece como uma "troca" negociada diretamente (habilitação em troca de serviços gerais).

Nesse subitem foi desenvolvida basicamente a ideia de que é possível apreender as relações políticas cotidianas na interação entre as esferas que perpassam desde o fogo familiar à família extensa -acrescida das relações de afinidade -, compreendendo assim um grupo que pode ser denominado como grupo de suporte.

\footnotetext{
${ }^{7} \mathrm{Na}$ língua guarani, o lexema "i” pode ser interpretado/traduzido com a conotação de diminutivo ou "pequeno", "menor", diferentemente do lexema "guasu" que conota aumentativo, como exemplo: "aty guasu" (grande reunião).
} 


\section{Grupos de suporte político e econômico do Pirakuá}

A Terra Indígena Pirakuá é composta basicamente por quatro regiões (Palmeiras, Ponte, Piri e Morro). Essas regiões não são de uso exclusivo de apenas uma parentela, porém é possível perceber que a formação de grupos de suporte econômico e político se conforma em relações de vizinhança. Ou seja, esses grupos são possíveis de serem aprendidos através da observação das relações de parentesco e afinidade imbricadas fortemente a aspectos da territorialização. Realizando uma análise, é possível verificar que cada uma das regiões apresenta características particulares na ocupação e na territorialização.

É importante ressaltar que os grupos de suporte $^{8}$ se conformam como uma espécie de unidade de cooperação que desempenham atividade de trocas com a finalidade de obter a produção e o consumo simbólico e material dessa unidade, que, em parte, podem ser identificadas com o "estilo de parentela".

Desse modo, esses grupos têm uma dinâmica sociológica atuando, dentre outras possíveis perspectivas, através das relações de parentesco e de afinidade que podem ser ativadas/positivadas através do estabelecimento de alianças. Essas relações de parentesco se positivam, ou seja, são rememoradas, passando de uma relação não tão próxima no passado a uma relação de proximidade e de cooperação com muita fluidez e elasticidade, mesmo que a consanguinidade ${ }^{9}$ seja algo difícil de comprovar, com muita rapidez e destreza política dos Kaiowa (PEREIRA, 1999). Não havendo regras de prescrição e de assentamento pósmatrimônio entre os Kaiowa, as agregações que formam os grupos de suporte se pautam, em muito, na capacidade do casal de articuladores (hi'u e há'i) de criar e recriar, de maneira quase ininterrupta, as demais esferas sociológicas que estão para além do fogo familiar - no caso o ñemoñare, juhuvy e em uma perspectiva mais ampliada dessas relações a te'yi e o tekoha.

Ouvi de alguns interlocutores a seguinte afirmação: "tal pessoa é meu primo". Isso ocorria quando ambos, o interlocutor e a pessoa referenciada, apresentavam idades equivalentes. Também escuteias qualificações "tal pessoa é meu sobrinho" ou "meu tio", utilizadas quando interlocutor e referenciado apresentavam idades e posicionamentos

\footnotetext{
${ }^{8}$ Acredito que o "grupo de suporte" deve ser compreendido em uma perspectiva de formação de redes complexas de relacionamento. Compreendendo que a sócio-lógica, e tudo que ela necessariamente implica para sua existência - associações, dissensos, cooperações, cisões, reciprocidades e relacionamentos que compõe e fragmentam, necessárias para a sua criação e permanência no tempo e no espaço. Ou como apresenta Viveiros de Castro (2006, p 298), “em sentido particular, (uma) sociedade é uma designação aplicável a um grupo humano com algumas das seguintes propriedades: territorialidade; recrutamento principalmente por reprodução sexual de seus membros; organização institucional relativamente autossuficiente e capaz de persistir para além da vida de um indivíduo; distintividade cultural”.

${ }^{9}$ Mesmo compreendendo que não é só pela consanguinidade que o parentesco se estabelece, é importante ressaltar sua relevância estrutural e fundadora de regras negativas que alicerçam e geram outras positivas, obrigando o estabelecimento da aliança para além das relações incestuosas.
} 
políticos diferentes o suficiente para que não pudessem pertencer à mesma geração ${ }^{10}$.

Um exemplo cotidiano dessa "elasticidade" das relações que sustentam os grupos de suporte econômico e político no Pirakuá pode ser observado em três conversas que mantive com um interlocutor, Lúcio, morador da região da Ponte. Em uma tarde, fui até a sua casa para fazer o meu trabalho de recenseamento. Durante nossa conversa, disse a Lúcio que estava hospedado na casa de Jorge, na região do Palmeiras, e prontamente ele afirmou que esse era seu primo. Em outro momento, conforme fui conhecendo melhor as famílias e as relações de parentesco do Pirakuá, percebi que Lúcio Gomes não era exatamente "primo" de Jorge, e sim um aliado político considerado como tal, pois ambos não têm nenhuma relação de parentesco concreta (através da consanguinidade). Vale observar que até mesmo outras pessoas da parentela de Lúcio não veem Jorge como um aliado político e, inclusive, fazem oposição e reclamam do tempo em que Jorge foi capitão" do Pirakuá.

Nesse caso, e em outros possíveis de observar no Pirakuá, percebemos que as apreciações de Viveiros de Castro sobre o parentesco amazônico, referenciadas em Dumont, fazem sentido no caso dos Kaiowa, pois a "afinidade engloba hierarquicamente seu contrário, a consanguinidade" (VIVEIROS DE CASTRO, 2006). Ao passo que a afinidade tem como matriz o relacionamento com o cosmos, a consanguinidade se constitui como "província do construído", ou seja, constitui a intenção e a ação de atualizar as relações humanas.

No caso dos Kaiowa, a identificação de uma relação de parentesco virtual $^{12}$ é a chave para uma aproximação e para o reconhecimento da aliança que, em seu cerne, surge de uma "afinidade potencial", que possibilita o desdobramento de relações de cooperação econômica e política.

\footnotetext{
${ }^{10}$ Um "caminho" para pensar as divisões geracionais talvez seja aquele com o qual tive contato durante a disciplina de Parentesco e Organização Social, oferecida pela PPGant/UFGD no primeiro semestre de 2012 e ministrada pelos professores Levi Marques Pereira e Márcio Silva. Durante as discussões na disciplina, foi possível pensar um modelo a partir do largo conhecimento e dos trabalhos do prof. Levi sobre a organização social kaiowa em apenas três gerações, que contavam, porém, com cinco categorias para a observação. A geração do ego (G0) que seria a "própria geração"; a G+1 uma geração acima de G0; a G-1 uma geração abaixo de G0. Sendo que as gerações acima de $\mathrm{G}+1(\mathrm{G}+2, \mathrm{G}+3, \ldots)$ são englobadas e reconhecidas pelos Kaiowa como uma única geração, a dos ascendentes (avôs e avós) ou tamoy (avô) e jarí (avó); as gerações abaixo de G 1 (G-2, G-3, ...) são reconhecidas pelos Kaiowa como a geração dos descendentes ou reamirirõ.

${ }^{11}$ Sobre o cargo ou posição de "capitão" a seguinte consideração deve ser feita: por mais que seja amplamente conhecido que essa figura - capitão - surge entre os Kaiowa e Guarani em Mato Grosso do Sul durante o processo de colonização realizado pelo indigenismo oficial do SPI e Funai (pós 1967), hoje esse cargo/posição é apropriado pela organização social kaiowa, tendo se tornado uma "coisa" kaiowa também. Desse modo, essa figura acaba sendo também um exemplo de chefia que acaba se evidenciando muito pela incumbência de resolver e desenvolver relações que dizem respeito principalmente ao funcionamento dos atendimentos de educação, saneamento e saúde na aldeia. No entanto, a pessoa que ocupa essa posição de status diferenciado acaba também sendo um chefe que se mantém pela referência da formação e manutenção do seu próprio grupo de suporte, que de maneira alguma deve liderar através de relações coercitivas baseadas no mando e na obediência.

${ }^{12}$ Definida por Viveiros de Castro (2006) como "afinidade potencial".
} 
Na segunda conversa, foi possível compreender que essa relação entre Lúcio Gomes e Jorge Gomes se dá muito mais no campo da afinidade e do reconhecimento de Jorge Gomes como cabeçante de um grupo, e por isso muito respeitado no Pirakuá, do que pelo campo do parentesco real ou de uma aliança efetuada pelo matrimônio, por exemplo. Nessa visita à casa de Lúcio Gomes, sua mãe, d. Mari, estava presente. Após ouvir minha resposta à pergunta "onde você está hospedado", d. Mari expressou uma reação de total desaprovação ao trabalho desenvolvido por Jorge como liderança no Pirakuá. Nesse momento Lúcio não se pronuncia, apenas abaixa a cabeça em tom de abnegação.

No terceiro momento que estive na casa de Lúcio, sua mãe, moradora da região do Morro, não estava presente e Lúcio claramente afirmou-me que Jorge era a "verdadeira liderança da terra", pois ambos eram muito amigos e Jorge o ajudava muito. E isso se confirmou pelas várias visitas que Lúcio fez a Jorge e vice-versa durante o trabalho de campo. Era comum, nessas visitas, combinarem trabalhos para cooperarem um com a atividade do outro. É importante dizer que no momento Lúcio construía uma nova casa, pois acabara de se casar novamente, e Jorge estava reformando o telhado de um galpão que tem em seu okarapy, onde são guardados o trator que fica na região do Palmeiras e também suas ferramentas.

Desse modo, a parentela extrapola o parentesco baseado apenas na consanguinidade. $E$ as relações dentro da categoria de análise proposta (grupo de suporte) extrapolam o parentesco concreto, expandindo-se também para o parentesco virtual, Desse modo, o grupo de suporte apresenta, em muitos momento, através de seu caráter econômico e político, o englobamento das relações consanguíneas pela afinidade ou pelo parentesco virtual. Como demonstra Pereira (2004) em sua tese sobre os Kaiowa, "pertence à parentela quem se identifica com o grupo, sendo que essa identificação passa necessariamente pelo reconhecimento da posição de liderança de seu cabeça" (PEREIRA, 2004, p. 102).

Portanto, os grupos de suporte do Pirakuá não são formados apenas por relações de parentesco consanguíneo. No entanto, é necessário ponderar o fato de que a parentela se apresenta como referência do grupo, muitas vezes identificado pelo nome de seu cabeçante, como um traço de diferenciação entre pessoas que compõem os grupos de suporte econômico e político diferentes.

Em uma análise sucinta das relações cotidianas, não é possível afirmar que, na política interna do Pirakuá, essas relações políticas e econômicas estejam baseadas na ideia de sociedades ameríndias "igualitárias" (CLASTRES, 2003; 2004).

Com o passar dos dias, na convivência, passa a ser cada vez mais evidente que a sociedade kaiowa é extremamente fragmentada, e nesse ponto é possível concordar com Pierre Clastres (2003): a organização se dá "contra o uno", ou seja, contra a formação de um poder institucional único, e, consequentemente, separado da sociedade. No entanto, é possível perceber um intenso "jogo" de disputas por espaços privilegiados 
de relacionamento dentro da parentela, na relação entre parentelas e nas relações com o entorno da sociedade.

Esse jogo ou essas disputas marcam uma forte hierarquia, deixando evidente que a capacidade de mobilização do cabeçante de um determinado grupo com a sua própria parentela e com os seus aliados marca o ponto possível de assumir uma ideia de unidade articulada através da representação de um grupo de suporte econômico e político, ou até mesmo, em momentos oportunos, da ideia de tekoha, principalmente em reuniões do conselho Aty Guasu' ${ }^{13}$ (grande reunião de lideranças de diversas TI e acampamentos kaiowa), em negociações com órgãos governamentais (como a Funai, Sesai, universidades) e não governamentais.

Desse modo, os grupos de suporte têm uma configuração fluída, porém hierarquizada, pois existe um "polo agregador", representado pelo casal de cabeçante da parentela, que centraliza relações sob si e tenta manter e ditar relações de produção, consumo e troca, que em momentos precisos, onde há agregação (como no caso das festas), testa seu prestígio e reconhecimento como pessoas que lideram um grupo. Nos casos de cisão e desentendimento - afinal, não podemos encarar a formação desses grupos de suporte apenas na perspectiva da composição -,, a capacidade da chefia é em muito testada pelo grupo que, de certo modo, aguarda que a chefia se utilize do prestígio e do reconhecimento que tem para pacificar (principalmente através da fala) e reorganizar as relações no interior do grupo.

Portanto, ao contrário do que foi aventado por Clastres (2003), isto é, que a sociedade antecederia o líder e este trabalharia em prol do desejo e da vontade daquela, na verdade, constatamos, no caso particular do Pirakuá, que o líder ${ }^{14}$ é aquele que cria/funda a sociedade.

\section{A chefia kaiowa e o prestígio}

Inicialmente já é possível pensar que o primeiro questionamento na introdução (o que seria esse status de prestígio) está diretamente relacionado à ocupação de uma posição de distintividade em relação à sociedade. Basicamente, esse "ocupar" um lugar socialmente distinto, nesse caso, se dá por um processo dialético. Dialético pelo fato de que, em um primeiro momento - diferentemente do que foi postulado por

\footnotetext{
${ }^{13}$ A Aty Guasu é uma reunião onde são convocados vários chefes políticos e religiosos. Esse encontro tem a finalidade de debater e resolver questões graves que ocorrem ao conjunto da população Guarani. Em Mato Grosso do Sul no ano de 2011 ocorreram duas Aty Guasu: uma em abril, na Terra Indígena Arroio Korá, no município de Paranhos (MS) e outra em agosto, na Terra Indígena Passo Pirajú, no município de Dourados (MS). Segundo Brand (fala gravada durante Aty Guasu na Terra indígena Arroio Korá em abril de 2011), a primeira Aty Guasu ocorreu em janeiro de 1978 na Terra Indígena Takuapiry.

${ }^{14}$ Quando falamos em um líder ou em uma chefia, temos que nos atentar para o fato de que a pessoa que tem o status de chefia, na maioria dos casos, entre os Kaiowa, um homem, na realidade ele só pode ocupar esse papel estando casado. Portanto, a liderança ou chefia é na realidade sempre a "síntese" de um casal que encabeça um grupo.
} 
Pierre Clastres -, a sociedade não preexiste à chefia, é necessário que essa sociedade seja criada. E é a chefia que se torna chefia por ter como papel fundamental a criação de seu próprio grupo de liderados. Já em um segundo momento, para que essa chefia continue a ser chefia, é preciso que o grupo a reconheça e a legitime como tal. E isso se dará através do prestígio, do apreço social que o grupo tem por essa pessoa-líder.

Para que a chefia mantenha um grupo entorno de si, é preciso muita habilidade. Inicialmente é enfrentado o desafio de criar o grupo e, em seguida, é preciso que ele seja mantido no tempo. Nesse segundo ponto, é possível concordar com as colocações feitas por Pierre Clastres (2003) em seu ensaio sobre a filosofia da chefia ameríndia. Cabe ao chefe ser um apaziguador, ser generoso com os bens que consegue através do seu trabalho de representante do grupo, ter a responsabilidade da palavra. Porém, não de qualquer palavra, mas sim de uma palavra que faz a reflexão que o grupo quer ouvir, que diagnostica os problemas e é capaz de convencer, pois como bem colocou Clastres (2003), convencer através da coerção, da ação de mando-obediência, é inaceitável- e isso é válido também no caso dos Kaiowa do Pirakuá.

Tanto Pierre Clastres (2003) quanto a pesquisadora Graciela Chamorro (2008) nos indicam caminhos quando discutem a palavra como um elemento essencial para o reconhecimento dessa liderança perante sua sociedade. Clastres afirma que "na obrigação exigida ao chefe de ser homem de palavra transparece, com efeito, toda a filosofia política da sociedade primitiva." (CLASTRES, 2003, p. 171). Na teoria de Clastres, de que é o "chefe" quem detém a obrigação e a responsabilidade pela manutenção da palavra nas sociedades indígenas, ela - a palavra apresenta-se como elemento essencial da cosmovisão dos povos Guarani e está intrinsecamente relacionada não só ao mundo material, mas também ao mundo extraterreno. Já Chamorro (2008), quando escreve sobre a cosmologia Guarani, complementa e dá foco para o grupo estudado neste trabalho, traduzindo os lexemas referentes à palavra da seguinte maneira:

Uma das associações mais frequentes com a qual se costuma traduzir os lexemas básicos (ñe'ẽ e ayvu) é palavra-alma, que é a palavra divina e divinizadora. (...) mas os termos em questão na associação palavra alma são ñe'ẽ e ayvu, que podem tanto ser traduzidos como 'palavra' como por 'alma' com o mesmo significado de 'minha palavra sou eu' ou 'minha alma sou eu' (CHAMORRO, 2008, p. 57-58).

$\tilde{N} e^{\prime e} e$ é uma das distinções do conceito de alma realizado pelos Kaiowa em Mato Grosso do Sul e também por outros grupos Guarani. Ñe'ẽ seria a alma espiritual, correspondendo à palavra-alma, e se manifesta através da fala, tendo sua morada, durante a vida das pessoas, na garganta (MELIÀ; GRÜMBERG; GRÜMBERG, 2008). 
Nesse mesmo sentido, Friedl Paz Grümberg (2003) complementa a importância da palavra e sua ligação com o sagrado:

En principio los guaraní distinguen dos tipos de alma. El alma espiritual ñe'e y el alma corporal ã. Los seres humanos poseen las dos durante toda su vida en la tierra. El alma espiritual se expresa por medio de la palabra, se ubica en la garganta y después de la muerte sale del cuerpo para regresar directamente a su 'morada celestial' que se encuentra en uno de los siete niveles celestiales (GRÜMBERG, 2003, p. 2).

Seguindo este caminho da importância da palavra, pretendo aqui levar adiante os debates referentes à atuação da liderança kaiowa. Tomo como ponto de partida a importância da palavra na atuação da liderança e na sua permanência como chefia, pois, enquanto essa puder realizar a manutenção desse elemento, essencial no fazer cotidiano da política entre os Kaiowa do Pirakuá, permanecerá em uma posição de prestígio em relação ao grupo. O simples fato de pedir a palavra, por exemplo, em uma reunião na aldeia, por qualquer motivo que seja, já é uma grande demonstração da posse desse status de prestígio.

Portanto, a reflexão possível é a seguinte: essa "posse", na realidade, acaba sendo posse por doação do grupo, doação do espaço para a fala e do respeito (e da responsabilidade) que o grupo apresenta durante a fala. Quando uma liderança está falando, por mais que pessoas pertencentes a grupos não aliados dessa liderança estejam ouvindo e não concordem com o posicionamento, jamais há uma situação de interrupção abrupta ou de retruque com truculência. Durante o tempo que permaneci no Pirakuá, foi possível acompanhar situações como essa, onde percebi claramente que o posicionamento de um grupo dos "ouvintes" era outro ao da liderança que estava falando; no entanto, aguardavam a fala terminar para assim serem conduzidos ao uso da palavra por outra chefia, que não necessariamente contrariava a fala anterior, mas sim buscava contornar os argumentos.

É possível perceber também o esvaziamento durante uma fala que não agrada algum grupo. Para suscitar melhor essa afirmação exponho uma breve observação feita durante o trabalho que desenvolvi como assistente de pesquisa em um levantamento de percepção de direitos no ano de $2011^{15}$ na Reserva Indígena de Dourados. Na referida experiência, estávamos (eu e o grupo que compunha o projeto) realizando um grupo focal com lideranças na aldeia Bororó. Na oportunidade, os participantes do grupo focal falavam sobre as suas perspectivas sobre diversos assuntos de interesses para a elaboração do relatório (saúde, segurança, alimentação, moradia, educação, etc.). Era perceptível a presença de ao menos dois grupos bastante distintos na reunião. Mesmo percebendo que

\footnotetext{
${ }^{15}$ UNICEF. Análise Comparativa do Grau de Conhecimento e Realização de Mulheres e Crianças Indígenas Em Dourados e Alto Solimões. Brasília, 2011.
} 
um dos grupos (o que estava em maior número) "monopolizou" a palavra, integrantes do outro grupo de lideranças não interferiram nas falas; no entanto, aos poucos foram esvaziando o local, até que ao fim do encontro do grupo focal restara apenas um dos grupos de lideranças, que, no caso, era composto pelo capitão, no momento, representado pelo vice.

A liderança não se relaciona com a sua sociedade pelo estabelecimento de um aparato de poder coercitivo. O que possibilita a sua atuação é o prestígio, ou seja, o grau de consideração que suas palavras, ações e representações podem alcançar perante a sociedade.

No entanto, a garantia de permanecer líder, ou de permanecer como um tendota (aquele que vai à frente), não se resume apenas no uso da palavra, É preciso considerar também a importância da demonstração e da manutenção de uma série de habilidades qualitativas que devem ser colocadas ao serviço da sociedade. Seria um erro crer que a atuação da liderança se efetiva como um exercício de aumento de poder principalmente se isso pressupor controle da violência e do mando de ordem na perspectiva da coerção -, sendo importante, nessa perspectiva, denominar essa atuação como uma busca, ou como o aumento e a manutenção do prestígio perante o grupo.

Da boca do chefe escapam não palavras que sancionariam a relação de mando-obediência, mas o discurso da própria sociedade sobre ela mesma, através do qual ela se proclama comunidade indivisa e desejosa de perseverar neste ser indiviso (CLASTRES, 1982, p. 108-109).

Um dos atributos da chefia é fazer o grupo "aparecer", visto que nem a liderança, nem o grupo já estão dados no universo, mas precisam ser criados. E nesse processo de construção, é a chefia que acaba se evidenciando como uma espécie de "polo agregador", encabeçando sua parentela e sendo reconhecido por outras parentelas e pessoas aliadas e afins como tal. Isso se evidenciou em alguns momentos em campo e também pode ser verificado nos trabalhos etnográficos de Pereira (1999; 2004), sendo comum ouvir-se que uma pessoa é da parentela de uma determinada pessoa; como dizem os Kaiowa, "fulano kuera"16.

Nesse movimento de criação realizado pela chefia ameríndia, é comum entre os Kaiowa que, na política cotidiana, sua voz afirme "sua unidade frente às outras unidades" (CLASTRES, 1982, p. 108), ou como afirma Sztutman:

Embora destituído de poder político como mando e coerção, o chefe possui um papel fundamental: criar uma aparência de unidade - identidade - capaz, de sua parte, de eclipsar a multiplicidade dos pontos de vista divergentes que poderiam irromper a todo

${ }^{16} \mathrm{O}$ termo kuera pode ser compreendido como coletivo de algo. 
momento. Nota-se que eclipsar não significa anular, tampouco aniquilar, pelo contrário. Não se trata de dissolver a heterogeneidade que compõe o social, mas dar a ela um ar de homogeneidade (SZTUTMAN, 2005, p. 255, destaques meus).

Essa atividade de representação de uma unidade, principalmente de falar pela ideia de unidade "da" e "para" a sociedade, requer muita habilidade, muito "jogo de cintura" do portador da fala, pois, o líder necessariamente precisará conciliar e apaziguar os diferentes conflitos que a comunidade apresenta para se manter na posição que ocupa e que é destinada a ele pelo corpo social.

Gallois (1988) também faz algumas contribuições nesse sentido, quando, em suas reflexões sobre a constituição dos grupos políticos entre os Waiãpi, expõe a relevância de se atentar para a importância da palavra que funda, unificando e dando sentido e identidade para o grupo - mesmo a partir de uma sociedade de composição evidentemente heterogênea. Esse caráter de unidade só é possível com um intenso trabalho da chefia de abrandamento dos conflitos. Um contínuo trabalho de pacificação das animosidades que se desenvolvem no interior da sociedade:

A estabilidade dessa unidade, enquanto associação de diversas famílias ligadas por laços de consanguinidade e de afinidade, depende do equilíbrio nas relações entre posições muitas vezes conflituosas: equilíbrio que deve ser garantido pelo chefe, cuja função é justamente 'falar e apaziguar' (GALLOIS, 1988, p. 22).

Portanto, a chefia, através de seu prestígio, de sua posição assimétrica de destaque em relação às demais pessoas que compõem a sociedade, funda e dá forma a um grupo - aqui entendido como grupo de suporte - ao qual ela "deve" um constante desempenho para permanecer como tal.

\section{Atributos qualitativos da chefia ameríndia}

A partir de Pierre Clastres (2003; 2004), uma preocupação se evidenciou durante o desenvolvimento deste texto: compreender por quais atributos qualitativos a chefia ameríndia - nesse caso, kaiowa precisa se articular para ser considerada uma liderança no momento contemporâneo.

Assim, inevitavelmente é necessário se atentar para o processo de contato pelo qual essas etnias passaram, desde o processo de esparramo, bastante estimulado pela concessão de terras a Cia Matte Larangeira (final do século XIX) e, depois, pelo incentivo na ocupação dos territórios do Centro-Oeste brasileiro nas décadas de 1940 e 1950 (criação da CAND em 1943), concomitante a um forte processo de confinamento realizado pelo 
Estado a essas populações, o qual se intensifica com o fim das derrubadas de matas e o incremento da mecanização da produção agrícola a partir da década de 1970, e em um outro momento, pelos movimentos de organização dessas etnias com o intuito de reclamar e retomar suas terras tradicionais, da década de 1980 em diante, que organiza processos próprios de luta e resistência - como é o caso do Pirakuá.

Desse modo, a chefia, basicamente, necessita estabelecer um forte domínio sobre os conhecimentos do mundo não indígena, ter um forte apreço valorativo e conhecimento das tradições, mantendo um equilíbrio entre ambos os conhecimentos; ser generoso e dedicado com seu povo; ser paciente; saber falar, levando em consideração sempre os parâmetros e os desejos de seu grupo; e realizar um trabalho de pacificação nos conflitos da comunidade.

Encontramos alguns desses traços nos escritos de Pierre Clastres, que, no entanto, apresentam em campo limites que extrapolam suas colocações - que não perdem sua validade, porém servem como parâmetro para iniciar a reflexão sobre tal tema que aqui se apresenta seguido de uma série de outros apontamentos feitos em outras etnografias.

Desse modo, Clastres afirma sobre tais atributos qualitativos:

Em um texto de 1948, Robert Lowie, analisando os traços distintivos do tipo de chefe anteriormente evocado, por ele denominado titular chief, isola três propriedades essenciais do líder índio, cuja recorrência ao longo das duas Américas permite apreender como condição necessária do poder nessa região:

[1] O chefe é um "fazedor de paz"; ele é a instância moderadora do grupo (...)

[2] Ele deve ser generoso com seus bens, e não se pode permitir, sem ser desacreditado, repelir os incessantes pedidos de seus "administrados".

[3] Somente um bom orador pode ter acesso a chefia (CLASTRES, 2003, p. 47).

A antropóloga Ana María Gorosito Kramer (2005) indica, em sua pesquisa realizada entre os M'bya de Misiones, na Argentina, outros elementos qualitativos da liderança que podem ser relacionados como "complementares" aos que foram expostos por Clastres. Sobre a liderança política (ruvicha), Gorosito Kramer (2005) afirma que essa é necessariamente encarregada de: 1) organizar a vida material e as atividades cotidianas; 2) gerenciar conflitos internos; 3) negociar com a sociedade nacional interesses do grupo ou da comunidade; 4) conhecer a tradição e ter domínio sobre os valores religiosos; 5) realizar um trabalho constante de consenso no interior do grupo; 6 ) ter domínio sobre a língua e os códigos da sociedade não indígena (oral e escrita) para poder, por exemplo, realizar a tradução e interpretação e elaboração de documentos. 
Segundo Wilde (2009), descrições dos jesuítas do século XVII já continham informações sobre a forma de atuação da liderança e de como se estabelecia a autoridade entre os povos indígenas, em que são muito valorizadas as relações que estas lideranças estabelecem com a sociedade, principalmente através de relações de parentesco e alianças. Tanto a família extensa quanto um grupo de famílias extensas (e, em um nível mais amplo, o tekoha - no caso Kaiowa e Guarani) compunham esferas políticas diferentes entre si e autônomas:

Cada uno de estos niveles (ruvicha o mburuvicha) que
mantenía relaciones de alianza o conflicto con los demás,
siendo flexible su posición en la que podrían acumular o
restar prestigio mediante la agregación-desagregación
de nuevos miembros para su grupo (WILDE, 2009, p.
101).

Para uma maior elucidação é possível recorrer às reflexões feitas por Lévi-Strauss em sua obra Tristes Trópicos na parte destinada ao grupo Nambikuara em Mato Grosso. Em seu artigo "Homens, mulheres e chefes" ele afirma que o "prestígio pessoal e a aptidão para inspirar confiança" (2010, p. 293) se constituem como elementos essenciais da política diária na sociedade Nambikuara. Se atentando também para a importância de a liderança ter um conhecimento sobre o território que o grupo ocupa - o que no caso dos grupos Nambikuara se constitui como algo de relevância, principalmente pela prática de ocupação nômade em um vasto território de perambulação.

Desse modo, acaba ficando sob a responsabilidade da chefia decidir, por exemplo, quais cultivos devem ser feitos e em qual lugar serão feitas as expedições de coleta e de caça. Só alguém com muitos conhecimentos das possibilidades territoriais e do entorno que compõe o território é capaz de liderar atividades de subsistência, passando a confiança que o grupo necessita para continuar a segui-lo.

A liderança, como já indicado, aparece nos trabalhos de Clastres como portadora de alguns atributos necessários para a manutenção desse status de prestígio, que não podem ser observados sem uma correlação de trocas consequentes ao "cargo"; essa liderança tem como cerne conter em si um "poder esvaziado", sem voz de comando (mando-obediência), em uma relação que não se baseia na noção de "poder" como controle de instrumentos coercitivos. Esse líder fica então na posição de fiel depositário da sociedade pela posição diferenciada que ocupa, confiada pela sociedade à pessoa do líder na forma de prestígio, ou seja, de respeito pelas suas capacidades de interpretação, tradução e pelos conhecimentos que tem sobre como manter o grupo coeso apesar das constantes contendas que surgem no convívio social.

A chefia, em troca dessa posição de prestígio, tem que recompensar a comunidade com palavras, interpretações, representações e, em momentos de maior importância para o grupo, terá o papel de exprimir 
reflexões sobre acontecimentos que ocorreram ou que estão ocorrendo na comunidade. Sobre a necessária capacidade de diagnosticar acontecimentos que dizem respeito direto ao grupo, postura desejável àquele que ocupa a posição de chefia, cabe um parêntese para uma reflexão feita durante uma observação. No ano de 2011, tive a oportunidade de passar um período curto, de apenas três dias, na aldeia Tenondé Porã, do grupo Guarani M'bya, localizada no município de São Paulo (SP).

Naquela oportunidade - possibilitada pela generosidade do colega e então também mestrando em antropologia Jan-Arthur Eckart -, pude acompanhar os encontros noturnos que aconteciam na casa de reza (opy). Segundo este colega, os encontros na opy são momentos de grande importância para a manutenção das relações de reciprocidade e dos laços sociais, voltados, principalmente, para práticas de cantos, rezas, conversas e brincadeiras. Em uma dessas oportunidades de estar na opy, pude observar um momento onde as lideranças da comunidade falavam sobre uma festa que havia ocorrido e que, de certa forma, entrava em desacordo com a imagem que gostariam que fosse passada da comunidade para a sociedade externa. As lideranças, uma a uma, fizeram falas trazendo à tona um discurso crítico e moralizante que desaprovava as músicas tocadas na festa e a presença de bebidas alcoólicas, ressaltando a importância de não deixarem que esses elementos da cultura do juruá (não indígena) passassem a fazer parte dos próximos momentos de confraternização da aldeia, pois isso poderia desmoralizar o grupo perante a sociedade envolvente à área que ocupam.

Lévi-Strauss ao escrever a Introdução à obra de Marcel Mauss, aponta que a troca se constitui como um elemento necessário às relações entre indivíduo e sociedade, sendo sempre fruto de uma construção. Essa troca não está posta para o etnólogo, necessitando a esse descobrir uma "fonte de energia que opere sua síntese" (MAUSS, 2003, p. 34).

Essa troca não é possível de ser visualizada simplesmente nos fatos. Só a observação empírica não é suficiente para fornecer às relações de trocas, mas sim "três obrigações: dar, receber e retribuir" (MAUSS, 2003, p. 33).

A troca não é um edifício complexo, construído a partir das obrigações de dar, receber e retribuir, com o auxílio de um cimento afetivo e místico. É uma síntese imediatamente dada ao e pelo pensamento simbólico que, na troca como em qualquer outra forma de comunicação, supera a contradição que lhe é inerente de perceber as coisas como os elementos do diálogo, simultaneamente relacionadas a si e a outrem, e destinadas por natureza a passarem de um a outro. (LÉVI-STRAUSS In MAUSS, 2003, p. 40-41).

É possível perceber que as apreciações de Lévi-Strauss ao escrever a introdução à obra de Marcel Mauss apontam uma importante nuance do 
trabalho de campo na pesquisa etnológica. A "dádiva" da troca não existe objetivamente, como uma propriedade física dos bens trocados, pois os bens trocados extrapolam os objetos físicos - como é o caso da relação que a liderança tem com a "obrigação da fala"; são trocadas dignidades, cargos, privilégios, prestígio etc. Dessa maneira, pela produção etnográfica e em algumas experiências de campo que tive a oportunidade de participar, é possível apontar a liderança política como uma liderança de parentela, como um "polo agregador" de outros parentes e pessoas afins em torno de suas qualidades de chefia.

No trabalho de Gallois com os Waiãpi, a liderança se constitui e é evidenciada como "polo agregador pelo fato do líder [deter] a primazia sobre a escolha dos sítios agrícolas, sobre os percursos de caça e coleta, justamente por ter ele 'reconhecido' a área ocupada pelo grupo" (1988, p. 23), onde Gallois complementa:

Prestígio acumulado pelos chefes em função de sua qualidade de 'fundador' e de 'organizador' nas atividades de subsistência, se relaciona diretamente com os laços de afinidade e, sobretudo, é reforçado pela regra de residência uxorilocal observada pelos Waiãpi (GALLOIS, 1988 , p. 23).

A partir destas colocações de Gallois, é possível fazer algumas considerações sobre os Kaiowa. Como já foi exposto, o status de prestígio da chefia se dá por conta da sua condição de cabeçante da sociedade, pela sua capacidade de criação e das articulações para a manutenção de um grupo de suporte. No entanto, em relação à necessária função desempenhada pelo parentesco nesse processo, o grupo Kaiowa se diferencia, pois não existem regras (como no caso Waiãpi) de residência nem prescrições de matrimônio, sendo determinante para a definição da residência pós-marital a capacidade de agregação desempenhada pelo cabeçante de um ou do outro grupo dos cônjuges. Nesse caso, a agregação ou desagregação será determinada, entre outras coisas, pela quantidade de prestígio acumulado pelo cabeçante, ou, no caso do casal, de referência do grupo de suporte.

Ao pensarmos a relação entre o líder e seu grupo, percebemos que o relacionamento vital da estrutura política se dá entre o líder e sua aldeia (RIVIĖRE, 2001). Ambos acabam sendo intimamente associados em uma relação de dependência, e dessa forma, a sociedade (na forma de aldeia) acaba dependendo, para a sua existência, da sobrevivência do líder. Em muitos casos, este acaba dando reconhecimento linguístico para o local de ocupação: "A aldeia é referida como lugar de determinado líder. [...] por ocasião de sua morte a aldeia normalmente é abandonada." (2001, p 106)

Para isso, para um bom relacionamento entre o líder e a aldeia, é necessário que a pessoa que está na chefia corresponda a uma série de 
atributos que são medidos pelos outros integrantes da aldeia de maneira qualitativa para a ocupação do cargo, na forma de competências.

Uma aldeia é acima de tudo um fenômeno social, e uma liderança bem sucedida deriva da capacidade de lidar com a rede social que constitui a aldeia e a comunidade. Isso exige a posse de determinadas competências (RIVIÈRE, 2001, p. 106).

Rivière elabora uma lista dessas qualidades/competências que são requeridas ao líder, as quais serão apresentadas logo abaixo de forma resumida, de maneira a facilitar a apreensão, pois é através delas que a permanência da aldeia se torna possível:

1. Comando de atividades: a liderança tem que buscar conciliar e favorecer a realização de atividades pelo seu próprio exemplo, sempre buscando uma postura que não se paute na distribuição de ordens e sim de exemplos;

2. Competência para formular julgamentos: é papel da liderança organizar e dar andamento a questões rotineiras de modo a saber determinar, por exemplo, a construção e o planejamento da aldeia e dos roçados; assim como auxiliar na composição do grupo nos momentos em que ocorrem desavenças e brigas por parte das demais pessoas que compõem a aldeia;

3. Falar bem: tanto "para fora" (discursos energéticos e diplomáticos) com a finalidade de representar a sociedade como uma totalidade una, quanto "para dentro" (discursos persuasivos) com a finalidade de convencer a sociedade a realizar atividades comunitárias, assim como a obrigação de apaziguar e mediar conflitos;

4. Generosidade: a liderança deve participar ativamente das redes de relacionamento de troca de bens e alimentos, assim como a recepção de visitantes ocasionais da aldeia;

5. Deter conhecimentos específicos: o líder deve ser um profundo conhecedor sobre os rituais, mitos, xamanismo e sobre o que diz respeito à tradição.

Como Clastres bem ressalta em sua Filosofia da chefia indígena (2003), o líder nas sociedades sem Estado (ameríndias) jamais se efetiva através do domínio de um poder coercitivo ou em relações estabelecidas através de comandos baseados em uma relação de mando-obediência.

Algo que o líder de modo algum se pode permitir é ser autoritário. O líder não tem meios de impor a sua vontade aos outros. Tendo em vista a baixa tolerância em relação a coerção (RIVIÈRE, 2001, p. 106). 
Porém, na prática é realmente muito difícil que uma pessoa que esteja ocupando um cargo de representação e que seja possuidora de uma série de conhecimentos sobre o passado e sobre a tradição não acabe extrapolando alguns limites. Para isso, Rivière aponta que existem duas exceções para o caso do líder se impor através da coerção.

A primeira exceção, demonstrada por Rivière no caso da Guiana, se relaciona à tolerância pela proximidade de parentesco com a liderança: quanto mais próximo o parentesco com o líder, mais fácil será a possibilidade de perdoar suas falhas. Sendo assim, torna-se menor a possibilidade de se considerar que as suas ações sejam autoritárias. Para este ponto, é interessante notar que, na maioria das sociedades indígenas, a liderança se constitui como uma pessoa agregadora de parentes $^{17}$, o que, no caso das sociedades ameríndias guianenses, se comprova pela forma preferencial de moradia uxirilocal ${ }^{18}$.

$\mathrm{Na}$ segunda exceção, a forma de poder coercitivo é baseada nas relações de gênero e de geração, pois o relacionamento entre homens e mulher e adultos e crianças "são autoritários até certo ponto e em ambos os casos os primeiros [homem, adulto] se encontram em condições de dizer aos últimos o que devem fazer" (RIVIÈRE, 2001, p. 107).

Um ponto importante desses processos de agregação e desagregação que pode também ser pontuado como um atributo qualitativo de responsabilidade da chefia é sua capacidade de articulação "para fora", seja, no caso do Pirakuá, na articulação com pessoas da cidade (prefeito, vereadores, comerciantes, gerentes de fazenda, etc.) ou na apropriação e distribuição de cargos e recursos advindos da presença do Estado para a terra indígena.

Desse modo, a chefia contemporânea kaiowa se constitui basicamente como alguém com atributos, ou seja, com uma atuação talvez muito parecida, estruturalmente falando, com a atuação de uma chefia em tempos passados. No entanto, a liderança contemporânea necessita hoje dominar conhecimentos da sociedade nacional e traduzilos para as demais pessoas do seu grupo.

\section{Considerações finais}

A chefia ameríndia constrói-se por caminhos outros aos quais estamos habituados quando pensamos a política e o poder nas sociedades não indígenas. No caso específico dos Kaiowa e Guarani e do

\footnotetext{
${ }^{17}$ Cf. PEREIRA, Levi Marques. Imagens Kaiowá do Sistema Social e seu entorno. São Paulo, SP: Tese de Doutorado, Antropologia Social da USP, 2004.; GALLOIS, Dominique Tilkin. O movimento na cosmologia Waiãpi: criação, expansão e transformações no universo. São Paulo: Tese de doutorado, Antropologia Social da USP, 1988.

${ }^{18} \mathrm{O}$ termo refere-se ao tipo de habitação praticada após o matrimonio, que no caso das sociedades guianenses se dá de forma uxorilocal, ou seja, após o casamento, o esposo vai morar junto a família de seu sogro.
} 
Pirakuá, percebemos que essa chefia só se torna chefia quando consegue, através de uma série de habilidades políticas específicas, tornar-se uma pessoa com traços distintivos em relação ao grupo, que só pode ser sustentado com o prestígio repercutido pelas ações dessa pessoa.

Diferente do que pensou Pierre Clastres $(2003 ; 2004)$ a sociedade não preexiste à liderança no caso Kaiowa; a liderança necessita, primeiramente, formar um grupo que, de forma centrípeta, permeará o entorno de suas decisões. Logo, o chefe é a pessoa que dá um caráter de unidade para determinado grupo, seja ele um núcleo parental mais restrito, estendido, ou mesmo com uma abrangência que pode chegar ao tekoha (tekoharuvicha) ou a ideia de povo Kaiowa e Guarani.

No entanto, devemos ponderar que a perspectiva apresentada por Pierre Clastres de que o poder não é concentrado na chefia e sim no corpo social também se conforma ao que pôde ser observado em campo, pois como bem coloca Etienne de La Boétie em sua obra Discurso da Servidão Voluntária (1982 [1574]), não existe servidão sem voluntariado, ou seja, não existem lideres sem que a sociedade (ou parte dela) o reconheça como tal. No caso dos Kaiowa, essa servidão pode ser observada. No entanto, jamais é operada pela liderança de modo a coagir seus liderados em uma relação de mando e obediência.

\section{Referências bibliográficas}

CHAMORRO, Graciela. Terra madura, Yvy Araguyje: fundamentos da palavra guarani. Dourados, MS: UFGD, 2008.

CLASTRES, Pierre. Arqueologia da violência. São Paulo: Editora Brasiliense, 1982.

A sociedade contra o Estado: pesquisas de antropologia política. São Paulo: Cosac Naify, 2003.

Arqueologia da violência. São Paulo: Cosac Naify, 2004.

EREMITES DE OLIVEIRA, Jorge; PEREIRA, Levi Marques. Ñande Ru

Marangatu: laudo antropológico e histórico sobre uma terra kaiowa na fronteira do Brasil com o Paraguai, município de Antônio João, Mato Grosso do Sul. Dourado, MS: UFGD, 2009.

GALLOIS, Dominique Tilkin. O movimento na cosmologia Waiãpi: criação, expansão e transformações no universo. 1988. Tese (Doutorado em Antropologia Social) - Universidade de São Paulo - USP. São Paulo, 1988. 
GOROSITO KRAMER, Ana María. Liderazgos guaraníes. Breve revisión histórica y nuevas notas sobre la cuestión. Montevideo: VI Reunión de Antropología del Mercosur, nov. 2005.

GRÜMBERG, Friedl Paz. La relación de los indígenas con la naturaleza y los proyectos de cooperación internacional. 2003. Disponível em:

$<$ http://guarani.roguata.com/articles/spa/gruenberg_relacion_indigena_naturaleza_2003. p df $>$. Acesso em 6 jun. 2018.

LA BOÉTIE, Etienne. Discurso da Servidão Voluntária. São Paulo: Brasiliense, 1982 [1574].

LÉVI-STRAUSS, Claude. Tristes Trópicos. São Paulo: Companhia das Letras, 2010.

MAUSS, Marcel. Sociologia e Antropologia - Prefácio de Claude Lévi-Strauss - São Paulo: Cosac Naify, 2003.

MELIÀ, Bartomeu; GRÜNBERG, Georg; GRÜNBERG, Friedl. Los Paĩ-Tavyterã: etnografia guarani del paraguay contemporâneo. $2^{\circ}$ edição (corrigida e ampliada). Asunción: 113 CEADUC/CEPAG, 2008.

PEREIRA, Levi Marques. Parentesco e organização social kaiowá. 1999. 235 f. Dissertação (Mestrado em Antropologia) - Universidade Estadual de Campinas Unicamp. Campinas, 1999.

PEREIRA, Levi Marques. Imagens kaiowá do sistema social e seu entorno. 2004. Tese (Doutorado em Antropologia) - Universidade de São Paulo - USP. São Paulo, 2004.

PERRONE-MOISÉS, Beatriz. Bons chefes, maus chefes, chefões: elementos de filosofia política ameríndia. Revista de Antropologia, São Paulo, n. 54, v. 1, p. 857883, 2011.

PRADO, José Henrique. Marçal de Souza Tupã'i: trajetória de um líder Guarani. 2010. 97 f. Trabalho de Conclusão de Curso (Graduação em Ciências Sociais) Universidade Federal de Mato Grosso do Sul - UFMS. Campo Grande, 2010.

PRADO, José Henrique. Através do prestígio: a atuação da chefia ameríndia entre os Kaiowa da Terra Indígena Pirakuá. 2013. 116 f. Dissertação (Mestrado em Antropologia) - Universidade Federal da Grande Dourados - UFGD. Douras, 2013.

RIVIÈRE, Peter. O indivíduo e a sociedade na Guiana: um estudo comparativo da organização social ameríndia. São Paulo: Editora da Universidade de São Paulo, 2001.

SAHLINS, Marshall. Âge de Pierre, age d'abondance. L'économie des sociétés primitives. Traduit de l'anglais par Tina Jolas. Préface de Pierre Clastres. Paris: Gallimard, 1976. 
SAHLINS, Marshall. O "Pessimismo Sentimental" e a Experiência Etnográfica: por que a cultura não é um "objeto" em via de extinção (Parte I). Mana, Rio de Janeiro, n. 3, v. 1, p. 41-73, 1997.

SZTUTMAN, Renato. O profeta principal: A ação política ameríndia e seus personagens. 2005. 485 f. Tese (Doutorado em Antropologia Social) - Universidade de São Paulo - USP. São Paulo, 2005.

UNICEF. Análise comparativa do grau de conhecimento e realização de mulheres e crianças indígenas em Dourados e Alto Solimões. Brasília, 2011.

VIVEIROS DE CASTRO, Eduardo. A inconstância da alma selvagem. São Paulo: Cosac Naify, 2006.

WILDE, Guillermo. Religión y poder en las misiones de guaraníes. Buenos Aires: Editorial SB, 2009.

Recebido em: 10/08/2017 * Aprovado em: 11/11/2018 * Publicado em: 27/06/2019 